\title{
Understanding and Analyzing Prescribing and Prescription Errors in Outpatient Setting of a Medical College Hospital ENT Department
}

https://doi.org/10.47210/bjohns.2021.v29i1.395

Rajiv Ranganath Sanji, ${ }^{1}$ Narendranath $V^{2}$ Chandrakiran $C^{3}$

\section{Introduction}

\section{$\underline{\text { ABSTRACT }}$}

A medication error is a failure in the treatment process that leads to, or has the potential to lead to, harm to the patient. In the hospital OPD, errors can occur in deciding on the medication to be prescribed (prescribing error) or in writing the prescription (prescription error).

\section{Materials and Methods}

We analyzed 100 prescriptions and case sheets in the OPD of ENT department in a tertiary medical college hospital for a period of one week for errors and assessed the perceptions and attitudes of the residents of the department using a questionnaire.

$\underline{\text { Result }}$

Several prescription writing errors were found, primarily failure to document non pharmaceutical patient advice and use of generic names. Four prescribing errors were noticed which did not need urgent intervention.

Discussion

Failure modes and effects analysis was done to rank the failures modes; and causes for failure were elucidated using Ishikawa Diagram. Recommendations for preventing errors were made based on these results.

Conclusion

This study illustrates the use of management techniques to identify errors and formulate appropriate preventive responses. Such techniques should be a part of ongoing departmental management; and they provide insights into improving resident training in an ENT residency program.

$\underline{\text { Keywords }}$

Drug Prescriptions; Prescription Audit; Medication Errors; Treatment Failure; Descriptive Counselling

$\Lambda$ medication error is a failure in the treatment process that leads to, or has the potential to lead to, harm to the patient.

Medication errors have been in the limelight following several important reports including the National Patient Safety Agency Report 2004 (UK) and the IOM Report 2000 (USA). ${ }^{1}$

In India, in the inpatient sitting, previous studies have observed medication errors to affect about $8.2 \%$ of inpatients. $^{2}$

The U.S. Food and Drug Administration (FDA) receives more than 100,000 U.S. reports each year associated with a suspected medication error.

Medication errors can occur in prescribing, prescription writing, manufacturing, dispensing, administering

1 - Department of ENT, RajaRajeswari Medical College and Hospital, Bangalore

2 - Department of Hospital Administration, M S Ramaiah

Medical College, Bangalore

3 - Department of ENT, M S Ramaiah Medical College,

Bangalore

Corresponding author:

Dr Rajiv Ranganath Sanji

email: rajivsanji@gmail.com 
medication or monitoring of therapy. ${ }^{3}$

A significant amount of literature about medication errors is based in the hospital setting, but these studies show variations in the type of clinical problems, classes of medications used and organization of services. This means that - the risks and the solutions required to prevent these er-rors or mitigate the risks will be different in different situations. ${ }^{4}$

It is our observation that at our outpatient department (OPD) majority of outpatient pre-scriptions are written by resident postgraduate students / interns working under the supervision of the faculty. No electronic medical record (EMR) or prescription writing software is used.

A methodology called failure modes and effects analysis (FMEA) is a helpful tool for iden-tifying and prioritizing errors that could occur in a process, rather than just reacting after an inci-dent has occurred. FMEA is already commonly used in hospital transfusion medicine and pharma-cies but can be used to improve any process. To create an FMEA, we brainstorm all of the different errors that could occur in an area or a process. ${ }^{5,6}$

Finding the root cause of a problem is important to devise solutions for preventing errors and solving the problem. When we have many causes leading to errors, standard tools like fish-bone diagram - also known as Ishikawa diagram can be used to simplify and classify the causes. A fishbone diagram is useful for breaking down a complex problem. ${ }^{7}$

The Medical Council of India (MCI) - from time to time- had issued guidelines for pre-scription writing, and also has issued a model prescription format for medical professionals prac-ticing allopathy in India. Although there have been observed deviations from norms observed in previous studies, the elucidation of cause and failure modes analysis in a medical college setting in our country was not found on literature search.

This study aims to identify, classify and analyze the prescribing and prescription errors at Otorhinolaryngology (ENT) OPD along with identifying perceptions of resident doctors about prescrip-tion writing to formulate recommendations for solving identified problems.

\section{Materials and Methods}

This observational study (Audit) analyzed the data from 100 consecutive prescriptions and case sheets of patients treated on OPD basis at Department of ENT at a tertiary care medical college hospital in a metropolitan city of South India - over a period of two weeks were photographed be-tween the second to third week of March 2020 and analyzed to identify prescribing and prescrip-tion errors compared to MCI model prescription $^{8}$, institutional prescription guidelines ${ }^{9}$, standard textbooks and standard practice.

All the postgraduate resident students of the department of ENT $(n=10)$ were asked for their feedback and inputs by survey.

Methods of Analysis: Simple measures of central tendency and proportions were used to analyze the data. Failure Modes and Effects Analysis (FMEA) table and Ishikawa diagram were used to analyze the failure modes and causes respectively.

Sampling and Sample size considerations: 102 consecutive prescriptions and case sheets in ENT OPD during the study period were photographed for the study. Two were excluded as the photo-graphs were blurry and not readable. Remaining 100 prescriptions were analyzed. Due to low number of outpatients during the study period, entire population was included in the study and random sampling was not done. Over a longer time period, the selection of the participants can be considered as a systematic convenience sampling. Audits are to be conducted repeatedly to correct identified errors and monitor the quality of work.

Ethical Considerations: No experimentation was done on humans in this study. The study was done as an academic and quality monitoring audit at the institution. Data obtained was from patient pre-scriptions and case records and no patient identifiable information is used. The primary investiga-tor constantly monitored the data being collected for significant errors. Consent was obtained from the residents to share the information obtained by personal interaction and questionnaire. 


\section{Results}

Ninety nine percent $(99 \%)$ of the prescriptions had appropriate patient identifying infor-mation. One prescription had incomplete patient identifier and only name was written. Of the pre-scriptions $3 \%$ had missing or incomplete date.

Thirty eight percent (38\%) prescriptions were written in capital letters, 40 were written in cursive hand but were legible without any problems, 22 prescriptions could be read with little ef-fort. None of the prescriptions were illegible or had problems of confusion with soundalike medications.

Only 3 prescriptions had generic drug names of the
100 prescriptions studied.

Only one prescription had non pharmaceutical advice documented. All the other prescrip-tions had drug details only.

Only 24 prescriptions had doctor name and Medical Council (MC) number written or im-printed with a seal along with signature. 76 prescriptions had incomplete/ missing doctor identifi-ers.

One each of the following errors in prescription writing were found:

1. Mis-spelt drug name

2. Additional drug in prescription - not mentioned in records

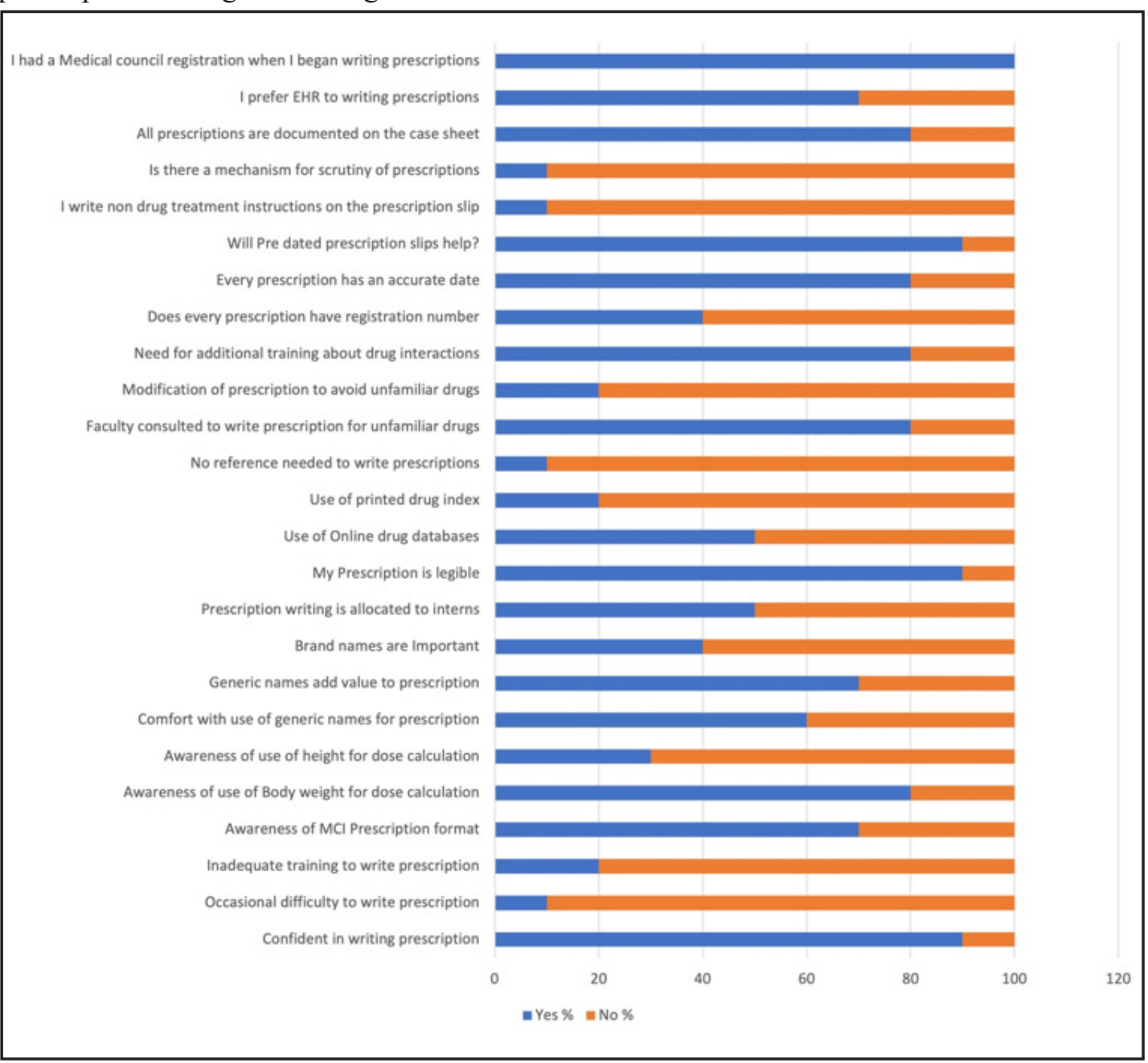

Fig. 1. Residents' perception of prescription writing 
3. Additional drug in records - not mentioned in prescription

4. Duration of prescribed drug treatment not written

5. Painkiller drug prescribed on SOS basis but maximum daily dose and dose spacing not mentioned.

Four prescribing errors were found, all were in paediatric age group patients. In all these prescriptions and records weight was not documented and used for dose calculation. In one of these prescriptions and records, there was no justification documented for use of non-standard an-tibiotic as compared to departmental protocol. In two of these prescriptions, maximum dose of an-tihistamine drug was prescribed and reason for the same was not documented. No error which were serious or potentially life threatening was found; hence no urgent corrective action was needed.

No errors of use of abbreviations or non-permitted abbreviations were found.

After initial analysis of the failure modes a survey form was prepared on Google forms and was filled online by all ten of the resident postgraduates of the department of ENT.

The results of survey of postgraduate residents about self-perception and opinion about pre-scription writing are shown in the chart above (Fig. 1).

The most common perception of benefit of using brand names was that it is easy to write for combination drugs $(90 \%)$, followed by perception of control of prescription cost with specified brands (70\%), easy recall $(60 \%)$, easy patient availability $(50 \%)$, avoidance of confusion $(30 \%)$, percep-tion of good quality of branded drugs (30\%). 30\% expressed concerns about issuing errors with ge-neric drugs and 10\% distrusted quality of generic drugs.

\section{Discussion}

Although a random sampling technique spread out over a period of time would eliminate biases and give a more representative sample, the purpose of the activity was to identify ongoing errors in prescribing and prescription writing, find the cause and give recommendations for inter-ventions to solve the problems found. A longer period of sample collection would defeat the pur-pose of the activity. It is suggested to have prescription audits as an ongoing activity to catch pos-sible failure modes early and have ongoing remedial activities as a dynamic quality improvement and quality sustaining program.

Failure Modes and Effects Analysis was done for all the errors detected and other possible errors not detected. The FMEA table is attached below. Risk priority number (RPN) was assigned by multiplying occurrence which was as per observations mentioned above - percentage reduced to a maximum of 10; as illegible handwriting and drug interactions were other possible failure modes which are possible but not observed occurrence of 0.01 was assumed. Detection score was made subjectively with 1 being not easily detected to 10 being easily detected. For severity of error, Na-tional Coordinating Council for Medication Error Reporting and Prevention (NCCMERP) severity index ${ }^{10}$ was available as a tool for ranking severity - however, it was found not to be suitable for this calculation as it correlates severity of error to the effect caused and here the effect of the error was not studied. Hence a subjective rating from 1-10 was used with 10 being most severe and 1 being the least. The FMEA table ordered by descending order of Risk Priority Number is shown in the table (Table I).

Probable causes were attempted to be elicited by personal interactions and survey of the postgraduate residents and the effects are contemplated and discussed. In addition, few additional causes such as difficulty of issuing written instruction in local language were uncovered by the survey.

Although majority of the residents (90\%) expressed that they were confident of writing the prescriptions and had received adequate training in writing prescriptions $(80 \%), 30 \%$ were not aware of MCI prescription format. All of them wanted additional training in writing prescriptions. This indicates openness to improvement and inadequacy of training of the residents for prescription writing.

$90 \%$ of the residents wanted more training about drug interactions and how to avoid them - this seems to be an area to be stressed on in the training program of the residents. 
Table I: Failure Modes and Effects Analysis (FMEA)

\begin{tabular}{|c|c|c|c|c|c|c|}
\hline $\begin{array}{l}\text { FAILURE } \\
\text { MODE }\end{array}$ & CAUSES & EFFECTS & 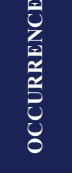 & 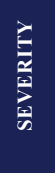 & 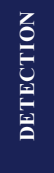 & $\mathbf{R P N}$ \\
\hline $\begin{array}{l}\text { 1. All } \\
\text { instructions not } \\
\text { written }\end{array}$ & $\begin{array}{l}\text { Prescription paper too small, } \\
\text { inadequate time to write, } \\
\text { if doctor does not know } \\
\text { patient's language - then he/ } \\
\text { she cannot write instructions } \\
\text { in patient's language. }\end{array}$ & $\begin{array}{l}\text { Patient takes drug } \\
\text { incorrectly or does } \\
\text { not follow important } \\
\text { nonpharmacological } \\
\text { advice }\end{array}$ & 9.9 & 3 & 10 & 297 \\
\hline $\begin{array}{l}\text { 2. Generic drug } \\
\text { names not used }\end{array}$ & $\begin{array}{l}\text { Not considered important, } \\
\text { not able to recall, patient cost } \\
\text { cannot be controlled, difficult } \\
\text { to write for combinations. }\end{array}$ & $\begin{array}{l}\text { Increased cost to } \\
\text { patient, reduced } \\
\text { patient choice, } \\
\text { reduced patient access } \\
\text { to drugs }\end{array}$ & 9.7 & 1 & 10 & 97 \\
\hline $\begin{array}{l}\text { 3. Doctor name } \\
\text { and MC number } \\
\text { not written }\end{array}$ & $\begin{array}{l}\text { Prescription is prepared } \\
\text { by junior/intern and not } \\
\text { checked; interns do not have } \\
\text { MC number stamp }\end{array}$ & $\begin{array}{l}\text { Cannot identify the } \\
\text { treating doctor easily } \\
\text { for review, pharmacist } \\
\text { cannot verify in case } \\
\text { of prescription for } \\
\text { scheduled drugs }\end{array}$ & 7.6 & 1 & 10 & 76 \\
\hline $\begin{array}{l}\text { 4. Incorrect dose } \\
\text { or duration in } \\
\text { children }\end{array}$ & $\begin{array}{l}\text { Body weight/ other dosing } \\
\text { considerations not taken, } \\
\text { preparations have varying } \\
\text { drug concentrations, } \\
\text { approximate dosing practice, } \\
\text { inadequate familiarity with } \\
\text { the preparations }\end{array}$ & $\begin{array}{l}\text { Inappropriate dosing, } \\
\text { increased risk of } \\
\text { complications or } \\
\text { therapeutic failure }\end{array}$ & 0.5 & 10 & 6 & 30 \\
\hline $\begin{array}{l}\text { 5. Date not } \\
\text { written or } \\
\text { incorrect }\end{array}$ & $\begin{array}{l}\text { Cannot recall date accurately, } \\
\text { Inadequate time to complete } \\
\text { prescription, Date field at top } \\
\text { of prescription in the printed } \\
\text { header }\end{array}$ & $\begin{array}{c}\text { Medicolegal risk, risk } \\
\text { of patient refilling } \\
\text { prescription, risk of } \\
\text { mix-up of medications. }\end{array}$ & 0.3 & 4 & 10 & 12 \\
\hline $\begin{array}{l}\text { 6. Incorrect dose } \\
\text { or duration }\end{array}$ & $\begin{array}{c}\text { Body weight or special } \\
\text { conditions not considered, } \\
\text { diagnostic uncertainty or } \\
\text { error }\end{array}$ & $\begin{array}{l}\text { Increased risk of drug } \\
\text { related complications } \\
\text { or therapeutic failure }\end{array}$ & 0.2 & 10 & 6 & 12 \\
\hline
\end{tabular}

Continued in the next page 
Table I (Contd.): Failure Modes and Effects Analysis (FMEA)

\begin{tabular}{|c|c|c|c|c|c|c|}
\hline 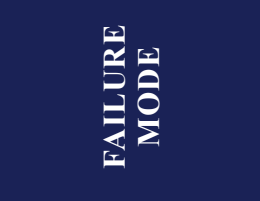 & $\begin{array}{l}0 \\
\frac{\pi}{5} \\
0 \\
2 \\
0 \\
0\end{array}$ & 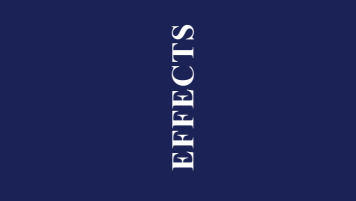 & 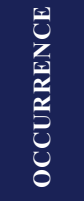 & 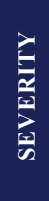 & 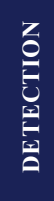 & $\underline{\underline{a}}$ \\
\hline $\begin{array}{l}\text { 7. Mismatch } \\
\text { between records } \\
\text { and prescription }\end{array}$ & $\begin{array}{l}\text { Forgets to enter record/ } \\
\text { prescription as the record } \\
\text { is not filled at time of } \\
\text { issuing prescription, patient } \\
\text { returns after some time } \\
\text { of consultation with fresh } \\
\text { complaint or demand for } \\
\text { medication }\end{array}$ & $\begin{array}{l}\text { Medicolegal risk, } \\
\text { risk of further errors } \\
\text { of prescription by } \\
\text { unavailability of data } \\
\text { in records, incomplete } \\
\text { therapeutic effect }\end{array}$ & 0.2 & 5 & 10 & 10 \\
\hline $\begin{array}{l}\text { 8. Drug } \\
\text { prescription } \\
\text { incomplete }\end{array}$ & $\begin{array}{l}\text { Uncertainty about duration of } \\
\text { treatment, Lack of awareness } \\
\text { of prescription protocol for } \\
\text { SOS medication }\end{array}$ & $\begin{array}{l}\text { Risk of overdosing/ } \\
\text { under dosing }\end{array}$ & 0.2 & 5 & 7 & 7 \\
\hline $\begin{array}{l}\text { 9. Patient } \\
\text { identification } \\
\text { incomplete }\end{array}$ & $\begin{array}{l}\text { Sticker not available, sticker } \\
\text { not printed correctly, patient } \\
\text { or doctor unwilling to wait for } \\
\text { file, pre prepared prescription } \\
\text { issued }\end{array}$ & $\begin{array}{c}\text { Risk of mix-up of } \\
\text { prescriptions between } \\
\text { patients, risk of missed } \\
\text { documentation in case } \\
\text { sheet, medicolegal } \\
\text { risks }\end{array}$ & 0.1 & 6 & 8 & 4.8 \\
\hline $\begin{array}{l}\text { 10. Drug } \\
\text { interactions not } \\
\text { considered }\end{array}$ & $\begin{array}{l}\text { Patient's drug history } \\
\text { unavailable/ not asked/ not } \\
\text { revealed, Poor knowledge } \\
\text { about drug interactions, } \\
\text { Newer drug interactions not } \\
\text { widely known }\end{array}$ & $\begin{array}{c}\text { Risk of adverse drug } \\
\text { reactions }\end{array}$ & 0.01 & 10 & 10 & 1 \\
\hline $\begin{array}{l}\text { 11. Handwriting } \\
\text { is illegible }\end{array}$ & $\begin{array}{l}\text { Doctor in a hurry, poor } \\
\text { handwriting and did not use } \\
\text { capitals, did not use EHR/ } \\
\text { EHR not available }\end{array}$ & $\begin{array}{c}\text { Drug mix-up, drug } \\
\text { missed }\end{array}$ & 0.01 & 4 & 3 & 0.12 \\
\hline
\end{tabular}

When in doubt while writing prescription, $80 \%$ respondents were comfortable with asking a faculty member or a more senior resident to guide them. Selfhelp using drug index ${ }^{11}$ or looking up online were at $40 \%$ and $60 \%$ respectively. Having a relatively good access to advice of seniors, few prescribing errors were found. Training regarding use of online prescription aids ${ }^{12,13}$ and drug indexes may be useful in improving confidence and competence of the residents.

Majority of the residents were aware of the required patient identifiers but were unaware of importance of documenting patient data like weight $(20 \%)$ and height
(70\%) which are important for optimally prescribing certain drugs whose dosages are body weight or body surface area de-pendent in their effectiveness. Continued awareness improvement and discussion regarding these points may help improve prescribing habits.

Although the Medical Council of India had made it unethical to write prescriptions without generic names ${ }^{14}$, it is observed that it is a common practice to use only brand names. Only 3\% of the prescriptions studied had drug names in generic. $40 \%$ of the residents had some discomfort in using generic drug names although none of them denied the usefulness of writing generic 


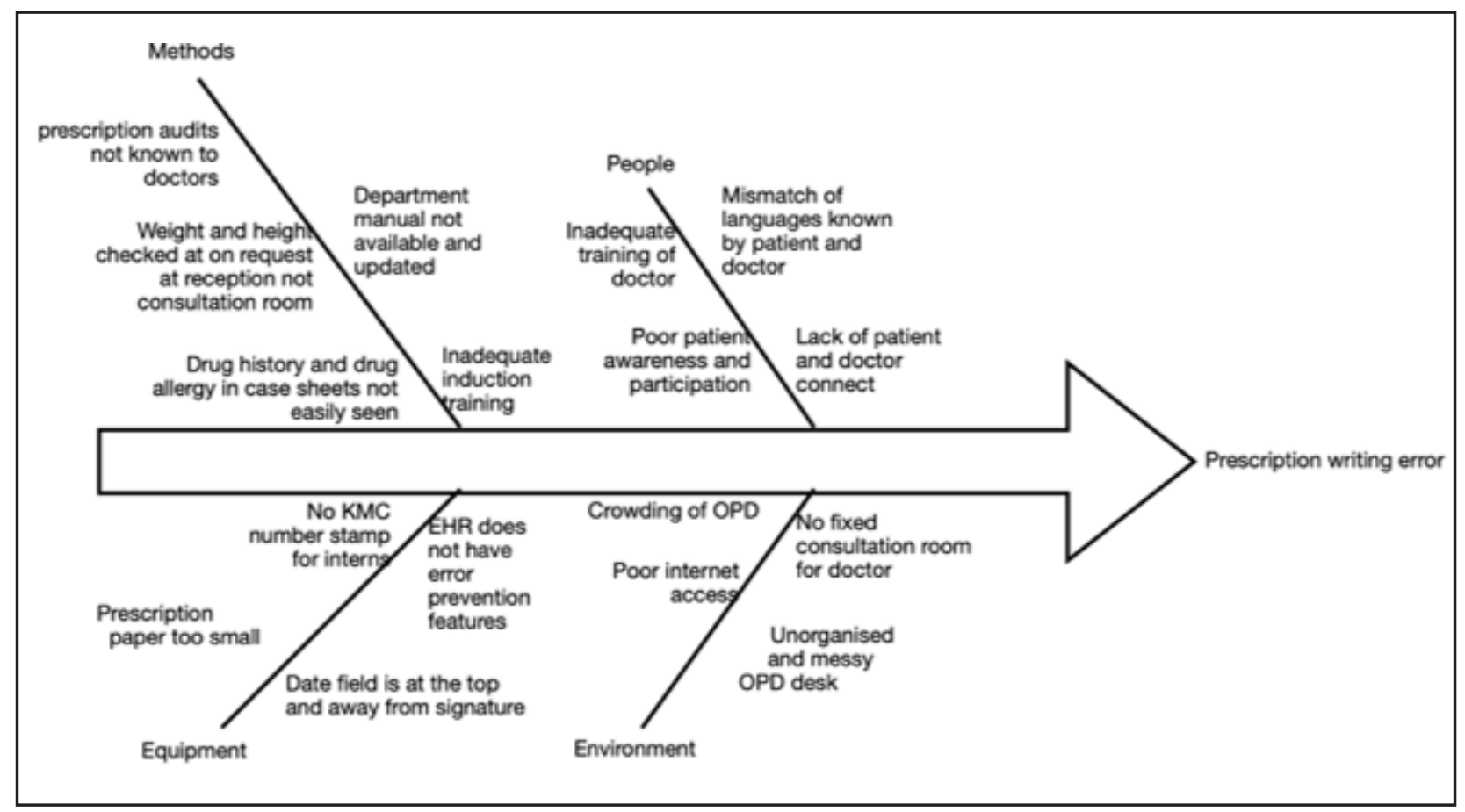

Fig.2. Prescription writing and prescribing error Ishikawa diagram

drug names in the prescription. Common reasons for preferring drug brand names over generic names include difficulty in recalling composition in multi drug combinations, ability to calculate and control the cost of the drugs prescribed by prescribing known brands, difficulty in recall of generic names and availability of generic drugs. These concerns reflect several systemic errors (as already discussed in available literature ${ }^{15}$ ) in the medical system which need to be addressed to improve use of generic drug names in prescription. Some minor issues also agreed upon were issues of trust in quality of generic drugs, confusions with generic names and lack of trust in the pharmacist to issue correct generic name medication.

The surveyed residents feel that about half of the time they don't write the prescriptions for the patients seen by them and they ask their juniors or interns to write the prescriptions and they also admitted that in such situations they don't always check the final prescription given to the pa-tient. Such delegation of duty may lead to errors creeping in due to communication barriers. ${ }^{16}$ Thus the prescription writing training also needs to include all levels of doctors including interns who rotate every 15 days among the departments. Thus, ongoing induction training for interns need to be considered and they should also be issued MC number stamp.

$97 \%$ of the prescriptions studied had date documented but $20 \%$ of the doctors felt that they sometimes miss out writing the date. As a possible intervention to reduce date related errors, ma-jority $(90 \%)$ were ready to accept date printed prescription slips on which date was printed or stamped before being placed in the OPD.

Although only one prescription had nondrug treatment and advice documented out of the 100 studied, $90 \%$ residents said that they sometimes documented the non-drug advice. Some rea-sons elicited with the survey for not documenting all the advice included - too small prescription paper size and difficulty in documenting the advice in a language understandable by the patient. These physical and social limitations need to be considered before recommending any intervention for this problem.

While $74 \%$ of the prescriptions studied had missing doctor identifiers (doctor name and $\mathrm{MC}$ number), $60 \%$ 
Table II: Recommendations for Failure Prevention

\begin{tabular}{|c|c|c|}
\hline FAILURE MODE & $\mathbf{R P N}$ & ACTION SUGGESTED \\
\hline $\begin{array}{l}\text { 1. All instructions } \\
\text { not written }\end{array}$ & 297 & $\begin{array}{l}\text { Increase prescription paper size to letter size from a5 size, prepare and use } \\
\text { instruction leaflets for common conditions treated in the OPD and for post- } \\
\text { operative care in local languages. }\end{array}$ \\
\hline $\begin{array}{l}\text { 2. Generic drug } \\
\text { names not used }\end{array}$ & 97 & $\begin{array}{l}\text { Additional concerns of the medical professionals need to be addressed to } \\
\text { propagate use of generic drug names. As these are systemic errors, correc-tion } \\
\text { has to occur at higher level. } \\
\text { Brand names may be permitted or stand-ard names to be given to essential } \\
\text { fixed combinations like anti cold preparations and cough syrups } \\
\text { Generic drug pharmacies may be in-creased in number and made more easily } \\
\text { accessible to prevent exploitation of the patient by the pharmacist who may } \\
\text { sell more expensive branded drugs to a pa-tient though generic prescription is } \\
\text { issued } \\
\text { Measures from government/ drugs con-troller of India /generic drugs manufac- } \\
\text { turers to doctors to address issues of trust and quality } \\
\text { At Institutional level, generic drugs to be stocked in hospital pharmacy - list of } \\
\text { the same to be shared to the doctors and above points may be implemented as } \\
\text { much as possible at institutional level. }\end{array}$ \\
\hline $\begin{array}{l}\text { 3. Doctor name and } \\
\text { MC number not } \\
\text { written }\end{array}$ & 76 & $\begin{array}{l}\text { Interns to be issued MC number identification stamps and included in } \\
\text { awareness and training programs for prescription writing. Or else clear policy } \\
\text { to be commu-nicated that interns should not write prescriptions. } \\
\text { Departmental induction training to be prepared and all new residents, interns } \\
\text { and faculty should be trained in prescription writing. At the time of joining MC } \\
\text { number stamp to be issued to all the doctors including interns. } \\
\text { It may be prudent to organize the workspace to include easy access to the } \\
\text { MC number stamp by marking space for the same and ensuring that they are } \\
\text { replaced after use. } \\
\text { Suggested to allot fixed consultation rooms for doctors - if necessary, by } \\
\text { rotation for a reasonable period of time to enable standardization of OPD } \\
\text { workspace. }\end{array}$ \\
\hline $\begin{array}{l}\text { 4. Incorrect dose } \\
\text { or duration in } \\
\text { children }\end{array}$ & 30 & $\begin{array}{l}\text { "Separate color prescription and file may be considered for pediatric } \\
\text { patients and high-risk patients like those with drug allergies or multi system } \\
\text { problems. Such pre-scriptions may be checked and signed by two doctors with } \\
\text { identification to avoid errors. } \\
\text { For high-risk groups, weight of the patient may be doc-umented on the } \\
\text { prescription at the department reception before sending the patient inside. } \\
\text { Induction training for new doctors to include sensitiza-tion for pediatric and } \\
\text { high-risk group prescription writ-ing. } \\
\text { Training for use of prescription writing aid software like UpToDate } \\
\text { Medscape or } \\
\text { Internet access to be ensured for all doctors in the hospi-tal to enable use of } \\
\text { prescription aids/lookup online. } \\
\text { Weighing scales and height measuring stand to be avail-able in each OPD } \\
\text { room." }\end{array}$ \\
\hline
\end{tabular}


Table II (Contd.): Recommendations for Failure Prevention

\begin{tabular}{|c|c|c|}
\hline FAILURE MODE & $\mathbf{R P N}$ & ACTION SUGGESTED \\
\hline $\begin{array}{l}\text { 5. Date not written } \\
\text { or incorrect }\end{array}$ & 12 & $\begin{array}{l}\text { Pre date-stamped prescription papers to be issued with file at reception to the } \\
\text { patient. All unused prescription papers to be collected and discarded safely. } \\
\text { Prescriptions when printed may be designed to have the date field below the } \\
\text { signature field where it will be visible clearly to prevent error of missing the } \\
\text { date. }\end{array}$ \\
\hline $\begin{array}{l}\text { 6. Incorrect dose or } \\
\text { duration }\end{array}$ & 12 & $\begin{array}{l}\text { Induction training for new doctors to include training for prescription of } \\
\text { commonly used drugs. } \\
\text { Department manual which has treatment protocol to be circulated among all } \\
\text { doctors in the department now and at induction. } \\
\text { Use of prescription writing aids to be encouraged. Barri-ers for junior residents } \\
\text { to approach faculty for clarifica-tions to be identified and addressed. }\end{array}$ \\
\hline $\begin{array}{l}\text { 7. Mismatch } \\
\text { between records } \\
\text { and prescription }\end{array}$ & 10 & $\begin{array}{l}\text { Consider use of non-carbon copy paper / pre inked copy paper for prescriptions } \\
\text { which will automatically transfer the written prescription onto the case sheet } \\
\text { when placed above the case sheet. }\end{array}$ \\
\hline $\begin{array}{l}\text { 8. Drug prescription } \\
\text { incomplete }\end{array}$ & 7 & $\begin{array}{l}\text { Consider use of preprinted prescriptions for commonly treated conditions to } \\
\text { reduce errors of prescription. }\end{array}$ \\
\hline $\begin{array}{l}\text { 9. Patient } \\
\text { identification } \\
\text { incomplete }\end{array}$ & 4.8 & $\begin{array}{l}\text { Patients not to be seen till case sheet arrives at OPD (but problem is possible } \\
\text { increased wait time for patient) - or patient identification sticker printer to } \\
\text { be available in OPD to be linked to the registration system to allow printing } \\
\text { of stickers of registered patient on demand in the OPD rather than printing } \\
\text { stickers at every visit at registration counter and sent with case sheet. }\end{array}$ \\
\hline $\begin{array}{l}\text { 10.Drug interactions } \\
\text { not considered }\end{array}$ & 1 & $\begin{array}{l}\text { Staff education and training programs to be conducted to improve knowledge of } \\
\text { drug interactions. } \\
\text { Drug allergy alerts and significant chronic illnesses to be printed in bold on the } \\
\text { first page of every outpatient case sheet - this page should not be used for any } \\
\text { other documentation. }\end{array}$ \\
\hline $\begin{array}{l}\text { 11. Handwriting is } \\
\text { illegible }\end{array}$ & 0.12 & $\begin{array}{l}\text { Although all checked prescriptions were legible, few cursive written } \\
\text { prescriptions had potential for error of interpretation. All doctors to be } \\
\text { encouraged to use capital letters for prescription writing. }\end{array}$ \\
\hline
\end{tabular}

of the residents also admitted that the prescriptions may have these details missing. All those surveyed were aware of these details needed in the prescription.

Two prescriptions had a mismatch with the documentation in the case sheet possible rea-sons include lack of time, patient seen before case sheet arrived and case sheet written later, and patient returns after some time with a request for another drug (e.g. painkiller).

All the residents are experienced with use of EHR at our other associated hospital, yet 30\% did not prefer to use an EHR for documenting and printing prescriptions. While electronic records have been proposed as a solution for several prescription error prevention strategies, it has been observed that they come with their own set of limitations and challenges. ${ }^{17,18}$

Ishikawa (Fishbone diagram) was constructed to organise the causes of prescription writing errors and organise thoughts about the same. (Fig. 2)

Failure prevention and early error identification actions are contemplated to eliminate or reduce the observed failures (Table II).

It is also necessary to have prescription audits which are scheduled, random and ongoing. At present $90 \%$ of the doctors felt that the prescriptions were not checked or did not know of any-one checking the prescriptions. 
The prescription audit reports may be shared with all doctors to enable recognition of errors and permit improvement of the prescriptions.

Scheduling of OPD visits by giving appointments and displaying estimated waiting time or waiting number will provide enough time to the doctor to see each patient and complete the pre-scription writing. It is also suggested to finish completely the consultation process for one patient before beginning with another patient.

Behaviour change communication and patient awareness posters relevant to the common diseases treated in the ENT OPD to be printed and displayed in the waiting area. Patient rights and responsibilities to be prominently displayed. Information about how patient can participate in his/her own treatment can be designed into posters and displayed in the waiting area. The residents should be exposed early in their training to community problems and given an opportunity to develop empathy for the patients.

Many of the errors may be addressed by using appropriate EMR software with error pre-venting mechanisms to detect inappropriate dose and drug interactions. However, the currently available EHR software at our Hospitals ${ }^{19}$ does not have error prevention mechanisms. A section of the doctors does not prefer using software for documenting the patient records as shown in the sur-vey $(30 \%)$. Hence the recommendations made are with a paper-based system in mind.

In addition to RPN, due to the severity of the effects, incorrect dose/duration and drug in-teractions need to be considered as priority for interventions to eliminate the errors.

The recommendations attempt to address the causes contemplated in the fishbone diagram. (Fig. 2)

\section{Conclusion}

Prescribing errors and prescription errors are preventable medication errors which can oc-cur in the ENT outpatient department. The errors usually have systemic causes which may be iden-tified by looking for errors, classifying them and analyzing the root cause. In this study, we ana-lyzed the prescriptions and after identifying errors, we identified the root causes - majority of which could be prevented by minor procedural and infrastructure changes. Training of all new res-idents and interns will increase awareness and help reduce the remaining few errors. The frame-work for error prevention and analysis is demonstrated in this paper. Ongoing prescription audits and analyses will improve quality of patient care in the ENT OPD and reduce errors. The goal of such audits should not be to place blame - but to identify and correct the root causes.

\section{References}

1. Williams D. Medication Errors. J R Coll Physicians Edinb [Internet]. 2007 [cited 2020 May 17];37:343-6. Available from: https://www.rcpe.ac.uk/sites/default/files/williams_1.pdf

2. Patel N, Desai M, Shah S, Patel P, Gandhi A. A study of medication errors in a tertiary care hospital. Perspect Clin Res. 2016;7(4):168

3. Aronson JK. Medication errors: Definitions and classification. Vol. 67, British Journal of Clinical Pharmacology. 2009. p. 599604

4. World Health Organization. Medication Errors Technical Series on Safer Primary Care Med-ication Errors: Technical Series on Safer Primary Care [Internet]. 2016 [cited 2020 May 17]. Available from: http://apps.who.int/bookorders

5. Graban M. Lean Hospitals Improving Quality, Patient Safety and Employee Engagement. Third Edit. 2016. 172 p

6. Institute for Healthcare Improvement: Failure Mode and Effects Analysis (FMEA) Tool [In-ternet]. [cited 2021 Feb 25]. Available from: http://app.ihi.org/Workspace/tools/fmea/

7. Graban M. Lean Hospitals Improving Quality, Patient Safety and Employee Engagement. Third Edition. 2016. p.161-2

8. Medical Council of India. Model prescription Format. MCI211(2)(Gen)/2014-Ethics/155202 India: Medical Council of India; 2015

9. Unpublished work: Department Manual of Department of ENT, M S Ramaiah Medical Col-lege Hospital

10. Hartwig SC, Denger SD SP, Hartwig SC, Denger SD, Schneider PJ. Severity-indexed, inci-dent report-based medica-tion errorreporting program. Am J Hosp Pharm [Internet]. 1991 [cited 2020 May 16];48(12):2611-6. Available from: https://www. nccmerp.org/types-medication-errors

11. Search Drug Information, Interactions, Images, Dosage \& Side Effects | CIMS India [Inter-net]. [cited 2020 May 16]. Available from: https://www.mims.com/india

12. Medscape Drugs \& Diseases - Comprehensive peer-reviewed medical condition, surgery, and clinical procedure arti-cles with symptoms, diagnosis, staging, treatment, drugs and med- 
ications, prognosis, follow-up, and pictures [Inter-net]. [cited 2020 May 16]. Available from: https://reference.medscape. $\mathrm{com} /$

13. Drugs \& Drug Interaction | UpToDate [Internet]. [cited 2020 May 16]. Available from: https://www.uptodate.com/home/ drugs-drug-interaction

14. INDIAN MEDICAL COUNCIL (Professional Conduct, Etiquette and Ethics) [Internet]. 2002. Available from: https:// www.nmc.org.in/rules-regulations/code-of-medical-ethicsregulations-2002

15. Andrade C, Sathyanarayana Rao TS. Prescription writing: Generic or brand? Vol. 59, Indian Journal of Psychiatry. Medknow Publications; 2017. p. 133-7.
16. Singla RK, Agrawal P, Sachan A, Jain P. Statistical Analysis of Medication Errors in Delhi, India [Internet]. Vol. 2, Indo Global Journal of Pharmaceutical Sciences. 2012. Available from: https://www.researchgate.net/publication/231294064

17. Hinojosa-Amaya JM, Rodríguez-García FG, Yeverino-Castro SG, Sánchez-Cárdenas M, Villarreal-Alarcón MÁ, GalarzaDelgado DÁ. Medication errors: electronic vs. paper-based prescribing. Experience at a tertiary care univer-sity hospital. J Eval Clin Pract. 2016; 22(5):751-4

18. Apple JL. The classification of medication errors. Nurs Manage. 1976;7(12):23-9

19. Sage Accpac by MIMSYS [Internet]. [cited 2020 May 16]. Available from: http://goaltech.net/wp-content/ uploads/2016/05/Mimsys-Sage-Solutions-For-Healthcare.pdf 